\title{
Competency Management and Learning Organization in a New Clinical Fieldwork Course
}

\author{
Supawadee Putthinoi ${ }^{1}$, Suchitporn Lersilp ${ }^{1} \&$ Nopasit Chakpitak ${ }^{2}$ \\ ${ }^{1}$ Faculty of Associated Medical Sciences, Chiang Mai University, Thailand \\ ${ }^{2}$ Chiang Mai University International College, Chiang Mai University, Thailand \\ Correspondence: Supawadee Putthinoi, Faculty of Associated Medical Sciences, Chiang Mai University, Thailand. \\ Tel: 66-5394-6041. E-mail: supawadee.p@cmu.ac.th
}

\author{
Received: February 19, 2015 Accepted: July 3, 2015 Online Published: November 25, 2015 \\ doi:10.5539/ies.v8n12p13 URL: http://dx.doi.org/10.5539/ies.v8n12p13
}

\begin{abstract}
As Thailand transitions into an ageing society, greater demands will be placed on healthcare systems. The concept of competency management and learning organization can be beneficial in continually expanding organizational capacity in order to create response. This study aimed to develop a new clinical fieldwork course in the community by utilizing competency-based development and assessment within the learning organization concept. Learning outcomes such as specification of programs, courses and field experience were designed under the competency standards of the Thai Qualifications Framework (TQF) for Higher Education and the World Federation of Occupational Therapists (WFOT). The household environmental risk management course was developed to support elderly people living in the community. It aligns with the new requirements for clinical fieldwork, which are guided by research and development (teaching, research and service) concepts. Course must provide a proactive approach with the potential to extend the capacity for continual learning, innovation and adaptation. Thus, academics can utilize research findings to improve the process, continually developing the quality and maturity of the organization over time.
\end{abstract}

Keywords: clinical fieldwork, community, competency management, learning organization, Thai qualifications framework

\section{Introduction}

\subsection{Introduce the Problem}

Facing an aging society trend in Thailand, the environment is one factor affecting the quality of life of the elderly. Falls are a significant risk in the elderly (National Committee on the Elderly, 2013) with high possibility falling because of age-related physiological changes (Rubenstein \& Josephson, 2006; WHO, 2007). Falls causing serious injuries and costs have become a major public health problem worldwide (Prasartkul, 2013). Injuries in the home caused by environmental hazards are very common in the elderly (Carter et al., 1997). A previous study (Putthinoi \& Chakpitak, 2011) on environmental hazards in the houses of older people found that a main problem was cluttered areas such as hallways, where it caused obstruction, and in rooms where it restricted movement, access to appliances and damaged floor. Improving the home environment to reduce injuries would be an effective preventive strategy to decrease the public health burden associated with demographic changes. The department of Occupational Therapy, Faculty of Associated Medical Sciences, Chiang Mai University (CMU) of Thailand produces health care professionals with a bachelor's degree in occupational therapy (Occupational Therapy Department, 2014). In the role of academic institute, it should respond to the current trend by equipping graduates with appropriate skills that focus on healthy living environments for older people. A new knowledge worker (Occupational Therapist) should have knowledge and skills to support new trend of ageing society and meet international standard.

\subsection{State Hypotheses and Their Correspondence to Research Design}

Competency in the skills, ability and capability to do the job contribute to human resources (HRs) meeting their goals in an organization. In a rapidly changing ageing environment, this concept is applied to define the entry-level competence in an occupational therapy (OT) service setting. The Professional Competencies for Occupational Therapists is a common set of competencies for all OT graduates. The essential requirement for all 
OTs is to practice competently within the profession, as determined by the World Federation of Occupational Therapists (WFOT) (World Federation of Occupational Therapists, 2008). Furthermore, in the Thai educational context, the Thai National Qualification Framework for Higher Education (TQF:HEd) contains the educational guidelines of the National Education Act, which comprises competencies and skills required for international accreditation, quality standard and quality assurance for Higher Education (Office of the Higher Education Commission, 2006). These frameworks provide a variety of curricula and teaching methods to assure the quality of graduates in their success in a career path, to the satisfaction of their employers.

Learning organizations are a good survival strategy and aid in being competitive in a complex environment. They have been applied to learning improvement in higher education in a new environment (Kolb and Kolb, 2005; Francis, 2014). Senge (1990) describes a learning organization as "an organization that is continually expanding its capacity to create its future". The OT Department of CMU represents a learning organization that should develop a new course according to new requirements, such as ageing trend, and determine the competency of a new informed OT worker (Occupational Therapist), who fits in with the context of competency standards (TQF and professional standard of the WFOT).

Thus, this research aimed to find a way for the learning organization to work better in supporting the ageing population, by combining theories that concern competency in management, and developing a new course for the OT Department, which responds to new trends in the ageing society. The benefit to the department is the continual extension of organizational capacity through research and development (teaching, research and service), or more maturity as an indicator of quality standards in educational institutions.

\section{Method}

A methodical case study was designed within the complex nature of this research, unlike a sampling research. It followed the principle and guideline according to Yin (2003) and Baxter and Jack (2008), and its approach provided a mode of inquiry for an in-depth examination of a phenomenon. For competency management with theoretical backgrounds; theoretical models were adapted to design and form an integrated research step. The main data collection techniques in this research were structured interviews, participant observation, group discussion, documentation analysis and questionnaires, as presented in Figure 1.

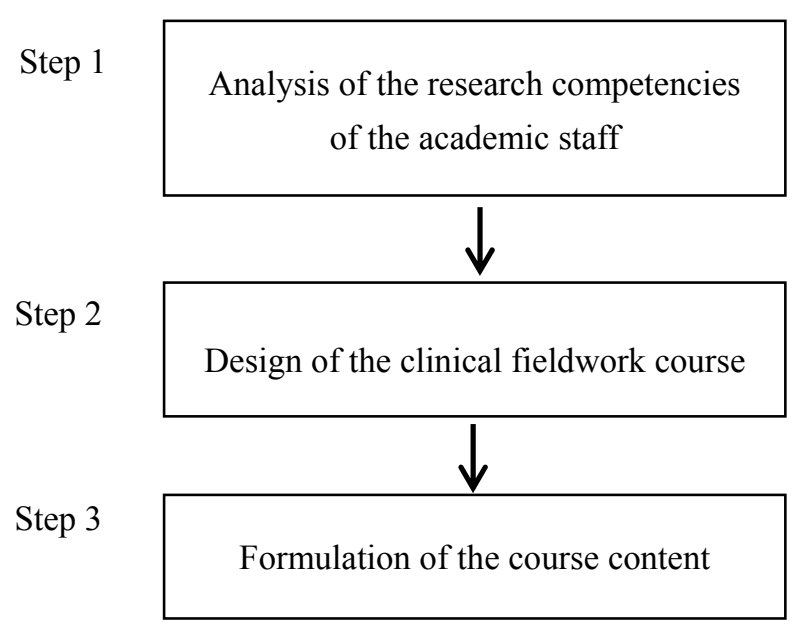

Figure 1. Research design

Firstly, analysis of the research competencies of the academic staff was part of the human resource in this academic organization. Academic staff in OT department is responsible both lecture and clinical fieldwork placement. This study focused on academic staff in the geriatric unit, by using an in-depth interview to capture the knowledge gained from their own research experience and their ideas about the risks in the home environment of the elderly. Content analysis and thematic extraction were used to analyze the transcripts, related documents and theme of research (Braun \& Clarke, 2006; Vaismoradi et al., 2013).

Secondly, the researcher used documentary research methods to study relevant documents (TQF 2: Bachelor of Science in Occupational Therapy), and the WFOT competency standard was investigated in order to formulate the new course. TQF 2 (Bachelor of Science in Occupational Therapy) was selected for analysis in the clinical 
fieldwork course (513445) because the objective of formulating the new course was to increase the efficacy of new therapists through clinical fieldwork. The new course was designed to allocate the development of learning outcomes and their importance in 6 domains of learning, as a clinical fieldwork course (513445). The development of learning outcomes in the domains of learning was investigated in three TQF 2 domains (knowledge, skills, and attitude), in accordance with the international standard of competency by using thematic analysis and coding.

Finally, the course content was formulated by analyzing the research domain of academic staff and standard of TQF competency in CMU using documentary analysis. Competency evaluation was determined at three levels according to Bloom's cognitive taxonomy (Anderson \& Karathwohl, 2001). The researcher constructed the new clinical practice course by analyzing the competency of students and competency level. Validity of the new course (age friendly housing for the elderly in the community) was conducted by the coordinator of the clinical fieldwork course. The comments and feedback given were very useful in enhancing, rectifying and improving contents of the new course.

\section{Results}

\subsection{Analysis of the Research Competencies of Academic Staff}

All of academics in the geriatric unit of the OT Department of CMU were five people. Their backgrounds and specialist/ research areas are presented in Table 1.

Table 1. Background of academic staff

\begin{tabular}{|c|c|c|}
\hline $\begin{array}{l}\text { Academic staff } \\
\text { in the geriatric unit }\end{array}$ & Educational background & Specialist/research area \\
\hline No.1 & $\begin{array}{l}\text { - Bachelor's degree (Occupational } \\
\text { Therapy) } \\
\text { - Master's degree (Neuroscience) } \\
\text { - Master's degree's (Counseling) }\end{array}$ & $\begin{array}{l}\text { - Impairment in the elderly and impact } \\
\text { on performance in the area of } \\
\text { occupation } \\
\text { - Intervention program and } \\
\text { rehabilitation } \\
\text { - Environmental modification }\end{array}$ \\
\hline No.2 & $\begin{array}{l}\text { - Bachelor's degree (Occupational } \\
\text { Therapy) } \\
\text { - Master's degree (Psychology) } \\
\text { - Doctorate degree (Curriculum and } \\
\text { Instruction }\end{array}$ & $\begin{array}{l}\text { - Student development } \\
\text { - Education } \\
\text { - Teaching and learning skills } \\
\text { - Curriculum development } \\
\text { - Lifelong learning }\end{array}$ \\
\hline No.3 & $\begin{array}{l}\text { - Bachelor's degree (Occupational } \\
\text { Therapy) } \\
\text { - Master's degree's (Physiology) } \\
\text { - Doctorate degree (Demography) }\end{array}$ & $\begin{array}{l}\text { - Device and adaptive device } \\
\text { - ADL training } \\
\text { - Elderly and well-being } \\
\text { - Successful ageing }\end{array}$ \\
\hline No.4 & $\begin{array}{l}\text { - Bachelor's degree (Occupational } \\
\text { Therapy) } \\
\text { - Master's degree (Neuroscience) } \\
\text { - Master's degree (Occupational } \\
\text { Therapy) }\end{array}$ & $\begin{array}{ll}\text { - The assessment and tool } \\
\text { development for therapy and } \\
\text { rehabilitation } \\
\text { - Treatment tools and program }\end{array}$ \\
\hline No.5 & $\begin{array}{l}\text { - Bachelor's degree (Occupational } \\
\text { Therapy) } \\
\text { - Master's degree (Public Health) }\end{array}$ & $\begin{array}{l}\text { - Retirement program } \\
\text { - Dementia prevention } \\
\text { - Fall prevention } \\
\text { - Health promotion }\end{array}$ \\
\hline
\end{tabular}


Two of academic staff members had completed a Doctoral degree in geriatrics, while three others held a Master's degree in medical science. Thus, their research areas were in accordance with their educational experience, and to some extent, their knowledge and specialization in serving the target group (the elderly), which is strongly related to their cognitive skills or educational background. The specialist and research areas are divided into 3 main areas as follows:

1) Health promotion

2) Rehabilitation

3) Educational research

The results of their own research ideas about risks in the home environmental for the elderly and reverse logistics (RL) were divided into five groups of research themes and issues as shown in Table 2.

Table 2. Research themes and issues in home environmental risk

\begin{tabular}{|c|c|c|}
\hline Research theme & & Issue \\
\hline \multirow[t]{5}{*}{ 1. Value, belief, motivation } & 1.1 & $\begin{array}{l}\text { Traditions, culture and belief in environmental management } \\
\text { within housing for the elderly }\end{array}$ \\
\hline & 1.2 & $\begin{array}{l}\text { Perception of home cluttering and home environmental risk for } \\
\text { the elderly }\end{array}$ \\
\hline & 1.3 & Motivation of the elderly in home management \\
\hline & 1.4 & $\begin{array}{l}\text { Expectations and needs of the elderly regarding their living } \\
\text { environment }\end{array}$ \\
\hline & 1.5 & $\begin{array}{l}\text { Appropriate media in home environmental risk management for } \\
\text { the elderly }\end{array}$ \\
\hline \multirow[t]{3}{*}{ 2. Behavior } & 2.1 & $\begin{array}{l}\text { Buying and consuming behavior of the elderly and use of } \\
\text { storage and disposal }\end{array}$ \\
\hline & 2.2 & Factors affecting motivation that lead to home maintenance \\
\hline & 2.3 & Health-related home maintenance behavior \\
\hline \multirow[t]{3}{*}{ 3. Home environmental risk } & 3.1 & $\begin{array}{l}\text { Home environmental risk management based on requirements of } \\
\text { the elderly }\end{array}$ \\
\hline & 3.2 & Problems and barriers of home environmental risk management \\
\hline & 3.3 & $\begin{array}{l}\text { Integration and sustainability of home environmental risk } \\
\text { management }\end{array}$ \\
\hline \multirow[t]{4}{*}{ 4. Reverse logistics (RL) } & 4.1 & $\begin{array}{l}\text { Knowledge about home environmental risk management of the } \\
\text { elderly in 3R (Reduce, Reuse, Recycle) }\end{array}$ \\
\hline & 4.2 & $\begin{array}{l}\text { Perceptions of the elderly and practitioners about cluttered } \\
\text { homes and home environmental risk by RL }\end{array}$ \\
\hline & 4.3 & $\begin{array}{l}\text { Development of an efficient system for donations and charity for } \\
\text { the elderly }\end{array}$ \\
\hline & 4.4 & $\begin{array}{l}\text { Effectiveness of } 5 \mathrm{~S}^{*} \text { implementation for home environmental } \\
\text { risk management }\end{array}$ \\
\hline \multirow[t]{3}{*}{ 5. Community } & 5.1 & $\begin{array}{l}\text { Analysis of the community system and society in leading to a } \\
\text { solution for home environment }\end{array}$ \\
\hline & 5.2 & Relationship between affordable housing and quality of life \\
\hline & 5.3 & Development of a prototype for a safe home for the elderly \\
\hline
\end{tabular}

*5S = Sort, Straighten, Shine, Standardize, Sustain. 
From these findings, new issues in research were identified by integrating their background with the research area of interest. Research, teaching and service are the fundamental roles of academic staff in a university. Thus, research conducted in the real-world supports academic service, which is then extracted for teaching-learning. This creates the key challenge of a more effective learning process for teachers on new relevant research frameworks and ideas for new actions.

The research issues in home environmental risk are analyzed and related to the international standards set by the WFOT research domain of the 2014 congress, as shown in Figure 2.

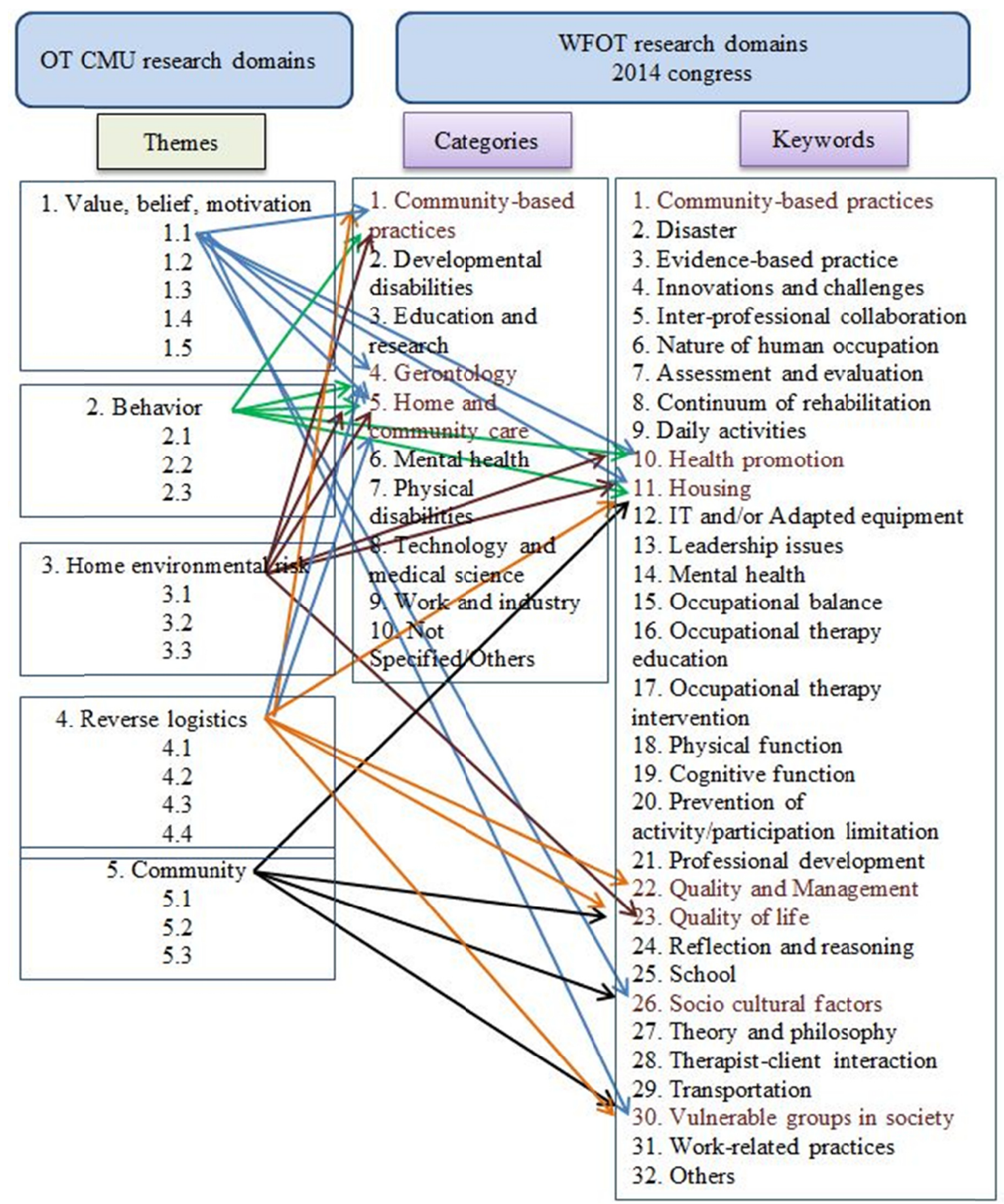

Figure 2. Research domain mapping 
The research themes of OT for CMU staff were investigated in relation with the WFOT research domains of the 2014 congress. All research themes mapped onto the WFOT research in the following categories:

1) Community-based practices

2) Gerontology

3) Home and community care

Additionally, themes of the research matched WFOT research keywords, as follows:

1) Community-based practices

2) Health promotion

3) Housing

4) Quality and management

5) Quality of life

6) Socio-cultural factors

7) Vulnerable groups in society

This finding shows that the research themes of OT staff in CMU follow the trend of international professional research.

\subsection{Clinical Fieldwork Course Design}

The researcher also began the process of analyzing the learning outcomes of the clinical fieldwork course of OT in CMU. The major responsibility of learning outcomes is expected in the domains of learning TQF 2 of the clinical fieldwork course (513445), as shown in Table 3.

Table 3. Major responsibilities in learning outcomes

\begin{tabular}{lllllllllllllll}
\hline TQF 2 & \multicolumn{3}{l}{ Morals and Ethics } & \multicolumn{3}{l}{ Knowledge } & \multicolumn{4}{c}{ Cognitive Skills } & ISR & NCT & Skills \\
\cline { 2 - 13 } 513445 & 1.1 & 1.2 & 1.3 & 1.4 & 2.1 & 2.2 & 2.3 & 2.4 & 3.1 & 3.2 & 3.3 & 4.3 & 5.3 & 6.3 \\
& $\bullet$ & $\bullet$ & $\bullet$ & $\bullet$ & $\bullet$ & $\bullet$ & $\bullet$ & $\bullet$ & $\bullet$ & $\bullet$ & $\bullet$ & $\bullet$ & $\bullet$ & $\bullet$
\end{tabular}

ISR $=$ Interpersonal Skills and Responsibilities.

$\mathrm{NCT}=$ Numerical Analysis, Communication and Information Technology Skills.

1) Morals and Ethics

1.1) Develop moral characteristics and ethical principles in academic and professional practice.

1.2) Have discipline, punctuality, personal and social responsibility, and respect for the rules and regulations of organizations and society.

1.3) Have leadership, fellowship and teamwork in resolving conflicts and priorities.

1.4) Respect the rights and listen to the opinions of others as well as respect the value and dignity of human beings.

2) Knowledge

2.1) Have knowledge and understanding about the principles and theories in an educational context.

2.2) Analyze problems, apply knowledge and skills, and use the right tools to solve problems.

2.3) Follow academic progression and have knowledge on a wide range of disciplines in order to realize the changes and understand the impact of new technologies.

2.4) Integrate knowledge into study related to other disciplines.

3) Cognitive Skills

3.1) Have critical and systematic thinking.

3.2) Search, gather, study, analyze and summarize issues in order to solve problems.

3.3) Apply knowledge and skill to solve problems properly. 
4) Interpersonal Skills and Responsibilities

4.1) Have the responsibility of self-development learning and professional development in continuity.

5) Analyze mathematical thinking, communication and information on technology skills.

5.1) Have efficiency and ability in communications; oral, written and presented.

6) Skills

6.1) Professional skills.

Competency is a set of related knowledge, skills and attitudes (KSA) associated with behavioral development and promotion. It enables an individual student in the learning processes to perform a task to the standard required for successful job performance, as development forms the basis of quality education. Furthermore, competencies often serve as potential measurement criteria for assessing competency attainment. However, KSA is a common component of performance indication in producing a list of grouped competencies that are required to perform successfully in a professional work setting.

In a review of standards set for OTs, this process validates competencies by matching them to appropriate international standards. Competencies in professional KSA in the OT practice of CMU compares with the competency standard of the WFOT, as shown in Figure 3.

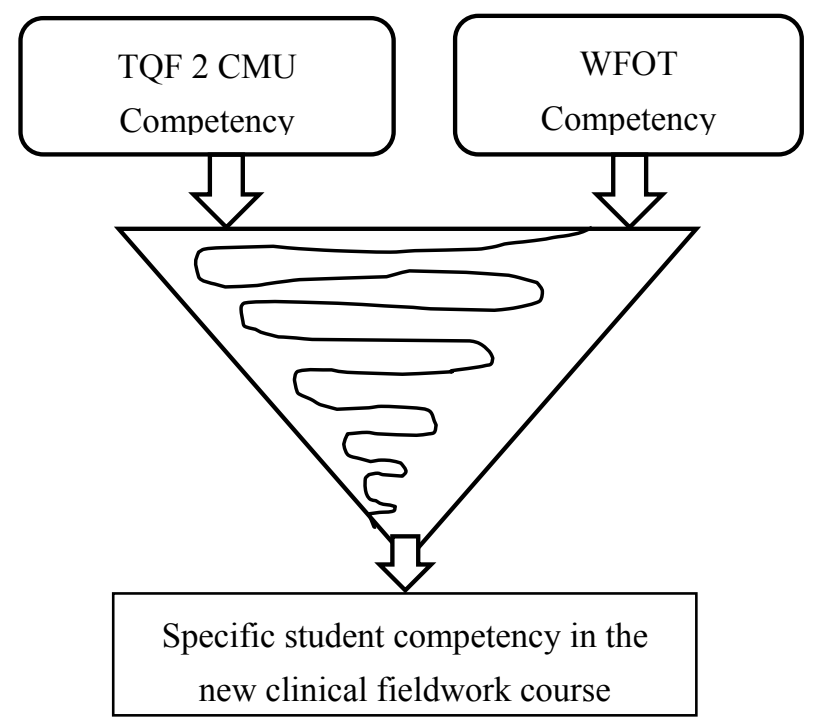

Figure 3. Integration of Thai and International competencies for the new course

The competency standard of OT in CMU relates and meets with that of the WFOT in developing professional OT skills. The competency of the occupational therapist is driven by the WFOT. The concept of competence in the professional practice of the WFOT focuses on what is expected of an occupational therapist. This course is designed to develop awareness of the role and importance of high-level professional attributes

Thus, clinical and fieldwork education is generally compulsory and a formally assessed component of professional courses within the new course of clinical fieldwork. The course is designed to integrate the research theme of academic staff with the competency standard of OT in CMU, and set an objective for a new course, as shown in Table 4. 
Table 4. Objective of the new course

\begin{tabular}{lll}
\hline Domains & Objective of the new course \\
\hline 1. Value, belief, & 1.1 & Understand traditions, culture and belief of the elderly and their lifestyle \\
motivation & 1.2 & Demonstrate respect for all persons and cultures \\
2. Behavior & 2.1 & $\begin{array}{l}\text { Understand and encourage behavior leading to awareness about the home } \\
\text { environment of the elderly }\end{array}$ \\
& 3.1 & Understand universal design, risk and barrier-free \\
3. Home environmental & 3.2 & Collect data /evaluation on risk according to the protocol \\
risk & 3.3 & Report information \\
& 4.1 & Analyze and develop a plan of RL \\
& 4.2 & Solve problems under the RL principles \\
4. Reverse Logistics & 4.3 & Act within the scope of RL \\
& 5.1 & Understand community living and the lifestyle of the elderly in the community \\
& 5.2 & Contribute knowledge of 5S* in order to manage home environmental risk \\
5. Community & 5.3 & Participate in the community in order to carry out implementation \\
\hline
\end{tabular}

$* 5 \mathrm{~S}=$ Sort, Straighten, Shine, Standardize, Sustain.

Learning objectives aim to describe what the learner should be able to achieve at the end of a learning period. The objective of the new course of clinical fieldwork is set as best practices in the field according to the research issues in home environmental risk, supply chain and RL of geriatric staff. Then, student competency in this new course is determined in order to provide a guideline for narrowing the focus specifically on geriatrics and the community, as presented in Table 5.

Table 5. Research domain and student competency

\begin{tabular}{|c|c|c|}
\hline \multicolumn{2}{|l|}{ Research domain } & Student competency \\
\hline \multirow[t]{4}{*}{$\begin{array}{l}\text { 1. Value, } \\
\text { motivation }\end{array}$} & 1.1 & $\begin{array}{l}\text { Explain links between the beliefs, values, motivation, tradition, culture and lifestyle } \\
\text { of the elderly }\end{array}$ \\
\hline & 1.2 & $\begin{array}{l}\text { Explain the importance of the values and beliefs of the elderly that affect their } \\
\text { motivation and lifestyle }\end{array}$ \\
\hline & 1.3 & $\begin{array}{l}\text { Analyze the beliefs, values, motivation, tradition, culture and lifestyle of the elderly } \\
\text { and how they relate to home management behavior }\end{array}$ \\
\hline & 1.4 & $\begin{array}{l}\text { Demonstrate the ability to interact with the elderly and others in the community } \\
\text { with respect for persons and culture }\end{array}$ \\
\hline \multirow[t]{4}{*}{ 2. Behavior } & 2.1 & Recognize the behavior, needs and lifestyle of the elderly \\
\hline & 2.2 & Analyze the behavior, needs and lifestyle of the elderly \\
\hline & 2.3 & $\begin{array}{l}\text { Demonstrate a good relationship with the elderly by non-judgmental and respectful } \\
\text { manners }\end{array}$ \\
\hline & 2.4 & $\begin{array}{l}\text { Demonstrate encouragement in the behavior of the elderly, leading to awareness of } \\
\text { their home environment }\end{array}$ \\
\hline \multirow[t]{4}{*}{$\begin{array}{l}\text { 3. Home } \\
\text { environmental risk }\end{array}$} & 3.1 & $\begin{array}{l}\text { Recognize the principle of housing conditions, home environmental risk, universal } \\
\text { design and barrier free }\end{array}$ \\
\hline & 3.2 & $\begin{array}{l}\text { Demonstrate data collection/evaluation on home environmental risk according to } \\
\text { protocol }\end{array}$ \\
\hline & 3.3 & Evaluate the level of hazards or risks \\
\hline & 3.4 & Prioritize problems based on the level of hazards and degree of risks \\
\hline
\end{tabular}


3.5 Write a report with information from evaluating the home environment, and complete an oral presentation

3.6 Combine the theories and principles into a new solution in order to carry out problem-solving by group conferences

4. Reverse logistics 4.1 Recognize the principles of RL

4.2 Construct and develop an implementation plan under RL

4.3 Evaluate problems under RL

4.4 Prioritize problems

5. Community

4.5 Apply implementation within the scope of RL

5.1 Recognize the principles of community life, and lifestyle of the elderly in the community

5.2 Analyze the elderly community

5.3 Utilize information from the community for analysis

5.4 Apply 5S in order to manage a home environment

5.5

Participate in the community in order to improve the homes and environment for the elderly

5.6 Apply efficient communication with the elderly and others in the community Work in the community with leadership, fellowship and teamwork, and resolve conflicts and priorities

5.8 Work in the community with discipline, punctuality, personal responsibility and a social conscience, and respect the rules and regulations of organizations and society Refer problems with care to appropriate persons when they are outside the scope of authority

Competency in the new course should be tailored to meet the developmental characteristics of the students, whose competencies use a simple and concrete language to explain the building of behavior and highlight the role of the learner.

\subsection{Course Content Formulation}

The clinical fieldwork in geriatrics and the community is designed from integrating the research theme of academic staff with the standard of CMU and WFOT competency. The new course of clinical fieldwork is shown in Figure 4. The new clinical fieldwork course has been designed and named as the "Age Friendly Housing Environment for the Elderly in the Community". The aim of this course design is to enable students to practice and refine the theory and skills they learned in the community. Students have opportunities to become an occupational therapist in the field of geriatrics, and put the theory into context in order to enhance the quality of education and professional development. 


\begin{tabular}{l} 
TQF 2 \\
$\qquad$ Field Experience Specification \\
\hline Section 1 : General Information \\
\hline 1. Institution Chiang Mai University \\
\hline 2. Faculty/Department Faculty of Associated Medical Sciences \\
Department of Occupational Therapy \\
\hline 3. Course Code 513447 \\
Course Name Age Friendly Housing Environment for The Elderly in the Community \\
\hline 4. 1(0-3-0) 45 hours \\
Section 2: Course Characteristics and Implementation \\
To carry out clinical fieldwork practice with supervision from the clinical supervisor by using the OT \\
process in evaluating and prioritizing problems, setting goals, and planning intervention and group \\
discussion as well as integrating the supply chain and RL into intervention, with the aim of enabling \\
Thai elderly people to live in their home and society with a sense of well-being, independence and \\
security. \\
Section 3 : Objectives of Field Experience \\
1. Understand the traditions, culture and beliefs of the elderly and their lifestyle \\
2. Demonstrate respect for all persons and cultures \\
3. Understand and encourage behavior that leads to awareness of the home environment of the elderly \\
4. Understand universal design, risks and barrier-free \\
5. Collect data /evaluate risk according to protocol \\
6. Report information \\
7. Analyze and develop a plan for supply chain operations reference (SCOR) model and RL \\
8. Solve problems under the SCOR model and RL principles \\
9. Act within the scope of RL \\
10 Understand community living and the lifestyle of the elderly in the community \\
11. Contribute knowledge on SCOR and RL in order to manage home environmental risk \\
12. Participate in the community in order to carry out implementation \\
\hline
\end{tabular}

Figure 4. The new course of clinical fieldwork

\section{Discussion}

This study found that competency management has been the tool for understanding the ongoing and articulated process of construction, and development of knowledge, skills and attitudes, from which individual staff research those areas, which are responsible for building and strengthening the competencies (self-development) of researchers, practitioners and those who support them and the community.

The research themes classified into five groups; 1) value, believe, motivation; 2) behavior; 3) home environmental risk; 4) reverse logistics; and 5) community, which have eighteen issues relating to the cluttered home, environmental risk of the elderly, and environmental risk management. The themes provide a basis from which the core competencies students need to develop can be derived. The themes also inform the academics about more effective learning process relevant research frameworks and graduate competencies.

This finding shows that the research themes of OT in CMU staff are relative to the main conceptual framework of research and trends in the international professional research, which is a significant tool that enables teachers to improve their teaching practices regularly and make their work more professional. Adler (1997) reported that teachers, as active researchers of their own practice, have developed particularly in contexts, where professional 
identity and practices of teachers are quite well formed. The research theme component is significant in crafting the course design that responds to the trends of an ageing society.

This course is provided as a clinical fieldwork placement of fourth-year students in order that they meet the requirements and learning objectives under the Thai Qualifications Framework for Higher Education (TQF). The study program in Thailand has to set the learning outcomes of the curriculum according to the TQF policy and July 2009 directive from the Office of Higher Education Commission (OHEC) (Tantirattanawongse, 2009). To empower graduate occupational therapists in the healthcare system, learning outcomes, the program, course and specific field experience are of the utmost importance and must be emphasized under the Thai National Qualification Framework for Higher Education (TQF:HEd).

The TQF was created with five domains of learning outcomes: 1) morals and ethics, 2) knowledge, 3) cognitive skills, 4) interpersonal skills and responsibilities, and 5) mathematical analytical thinking, communication skills, and information technology skills. However, TQF 2 of the OT Department of CMU added skills as one more domain of learning outcome for clinical fieldwork. Therefore, there are now six domains of learning outcomes in the new clinical fieldwork course of OT at CMU.

The new clinical fieldwork course is designed as a part of community experience in the geriatric unit, under course contents of clinical fieldwork III. These practicum experiences in the OT curriculum at CMU provide the students with an opportunity to translate theory into practice and observe or define the roles of OT in various clinical settings. The study of Petersson (2009) revealed that focusing on safety and security in tasks of everyday life performed by older adults is new knowledge related to the elderly and it should contribute to clinical practice not only for occupational therapists, but also other professionals. Therefore, this new course was developed to improve student competency in accordance with new trends of age society.

\section{Conclusion}

Academic staff expressed ideas of their own research after completing implementation of the new clinical fieldwork. This reflection involved the same research area as before the course was implemented, but with more crafted detail after teaching practice in a real situation. The research picture of academic staff is clearer in the area of a friendly housing environment for the elderly in a community that shares vision in these research themes, and provides improvement by learning through this clinical fieldwork, as learning is a never-ending process. Senge (1990) defined a learning organization as “... a place where people continually expand their capacity to create results they truly desire, where new and expansive patterns of thinking are nurtured, where collective aspiration is set free and where people are continually learning how to learn".

The OT Department of CMU is a learning organization where people continuously learn and enhance their creative capabilities. It is important for humanity to gain knowledge, improve and innovate continuously in order to be successful in new worldly situations by learning to learn more effectively. The new situation in this study is the Thai ageing society, which needs new appreciation of the knowledge and skills of clinical practice to enhance productivity and development. Student occupational therapists are known to contribute to development of clinical practice.

Implementation of competency management is applied to define entry-level competencies of health professionals among academic staff and students, as a human resource, and widen a new capacity for continual learning, innovation, and adaptation during the trend of an ageing society.

\section{Acknowledgments}

This research was supported by the Graduate School, Chiang Mai University. The authors would like to thank the reviewers and editor for their helpful in improving the quality of paper.

\section{References}

Adler, J. (1997). Professionalism in process: Mathematics teacher as researcher from a South African perspective. Educational Action Research, 5(1), 87-103. http://dx.doi.org/10.1080/09650799700200016

Baxter, P., \& Jack, S. (2008). Qualitative case study methodology: Study design and implementation for novice researchers. The Qualitative Report, 13(4), 544-559.

Braun, V., \& Clarke, V. (2006). Using thematic analysis in psychology. Qualitative Research in Psychology, 3(2), 77-101. http://dx.doi.org/10.1191/1478088706qp063oa

Carter, S. E., Campbell, E. M., Sanson-Fisher, R. W., Redman, S., \& Gillepie, W. J. (1997). Environmental hazards in the homes of older people. Age and Ageing, 26, 195-202. 
Francis, D. E. (2014). Lean and the learning organization in higher education. Canadian Journal of Educational Administration and Policy, 158, 1-23.

Kolb, A. Y., \& Kolb D. A. (2005). Learning styles and learning spaces: Enhancing experimental learning in higher education. Academy of Management Learning \& Education, 4(2), 193-212.

National Committee on the Elderly. (2013). Situation of the Thai elderly 2012. Thailand: SS Plus Media Company Limited.

Occupational Therapy Department, Faculty of Associated Medical Sciences, Chiang Mai University. (2014). SAR-OT. Retrieved January 6, 2015, from http://www.otinthailand.org/index.php?lay=show\&ac=article\&Id $=539676777$

Office of the Higher Education Commission. (2006). National qualifications framework for higher education in Thailand: Implementation handbook. Bangkok Thailand: Office of the Higher Education Commission.

Petersson, I. (2009). Everyday life and home modification for older adults. Stockholm: Karolinska Institute.

Prasartkul, P. (2013). Population aging and health: A case study of Thailand. In Keynote Lecture Presented at the RGJ-PhD Congress XI. Chonburi, Thailand: IPSR Publication.

Putthinoi, S., \& Chakpitak, N. (2011). Environmental hazards in the housing of older people from the academic staff of AMS, CMU. In processing of the 11th Annual SEAAIR Conference. University Social Responsibility: Pathways to Excellence, November 2-4, 2011. Chiang Mai, Thailand.

Rubenstein, L. Z., \& Josephson, K. R. (2006). Falls and their prevention in elderly people: What does the evidence show? Medical Clinics of North America, 90, 807-824. http://dx.doi.org/10.1016/j.mcna.2006.05.013

Senge, P. M. (1990). The fifth discipline: the art and practice of the learning organization. USA: Doubleday Dell Publishing Group, Inc.

Tantirattanawongse, J. (2009). Thai qualifications framework for higher education 2009 (TQF: HEd). Thailand: Commission on Higher Education.

Vaismoradi, M., Turunen, H., \& Bondas, T. (2013). Content analysis and thematic analysis: Implications for conducting a qualitative descriptive study. Nursing and Health Sciences, 15, 398-405. http://dx.doi.org/10.1111/nhs.12048

White, E., \& Creek, J. (2007). College of occupational therapists' research and development strategic vision and action plan: 5-Year Review. British Journal of Occupational Therapy, 70(3), 122-128. http://dx.doi.org/10.1177/030802260707000305

World Federation of Occupational Therapists. (2008). Entry Level Competencies for Occupational Therapists. Standards \& Quality Programme, WFOT.

World Health Organization (WHO). (2007). WHO global report on falls prevention in older Age. France, WHO Press: World Health Organization.

Yin, R. K. (2003). Case study research: Design and methods (3rd ed.). CA: Thousand Oaks, Sage.

\section{Copyrights}

Copyright for this article is retained by the author(s), with first publication rights granted to the journal.

This is an open-access article distributed under the terms and conditions of the Creative Commons Attribution license (http://creativecommons.org/licenses/by/3.0/). 